\title{
Didáctica de la edad media en educación infantil
}

DOI: $10.46932 / \operatorname{sfjdv2n1-049}$

Received in: November 1st, 2020

Accepted in: December 30th, 2020

\author{
Jose María Rabal Alonso \\ Profesor ISEN Centro Universitario \\ Institution: Universidad de Murcia \\ Calle Campus Universitario, 12, 30100 Murcia \\ E-mail: josemaria.rabal@um.es \\ Laura martínez gallego \\ Graduada Educación Infantil \\ Institution: RG Formación \\ Calle Rosalía de Castro, 44, 30107 Murcia
}

\section{RESUMEN}

Este artículo versa sobre ''La época medieval'. Hemos elegido este tema porque consideramos que es de vital importancia conocer la historia y el pasado de nuestro entorno, de una manera adaptada a Educación infantil, a fin de que puedan interiorizar la noción del tiempo, a la vez que aprenden sobre otras culturas pasadas.

Como menciona Tonda (2001), 'comprender un fenómeno significa, también, decir cuando sucedió. Ayudar al niño a conocer su medio para dominarlo, implica también ayudarle a analizar el tiempo" Además, se presenta un proyecto dirigido a niños de 5 años de tercero de Educación Infantil en el que se muestra, de manera práctica, la información presente a lo largo de la fundamentación teórica.

Palabras clave: organización escolar, metodología, desarrollo, currículo, niños, niñas.

\section{FUNDAMENTACIÓN TEÓRICA}

Restrepo (2015) señala que el Aprendizaje basado en problemas (ABP) es un método didáctico, cuya estrategia se basa en la enseñanza por descubrimiento y construcción. En este tipo de enseñanza, no es el docente el protagonista del proceso de enseñanza-aprendizaje, sino que es el alumnado el que selecciona la información, la organiza e intenta resolver problemas con ella. El papel de docente se queda en segundo plano, siendo este un guía y un orientador de dicho proceso.

Bruner es considerado el gran constructivista del XX y el encargado de sistematizar el aprendizaje por descubrimiento y construcción. Él considera que el aprendizaje no es solo recabar información, sino aprender a aprender y a resolver problemas (citado en Restrepo, 2015).

Consideramos que una de las ventajas del $\mathrm{ABP}$ es que parte del interés de los niños, por lo que las actividades programadas siempre están sujetas a cambios, dependiendo de la motivación que tengan estos. Además, cada niño trae una información diferente, por lo que es posible que se produzcan más 
aprendizajes de los esperados inicialmente y, por otro lado, los niños descubren que es posible aprender de sus compañeros.

La Edad Media es un periodo histórico que comprende desde el S. V (con la caída del Imperio romano de Occidente) y el S. XV (con el descubrimiento de América). Está comprendida entre la Edad Antigua y la Edad Moderna. Además, algunos historiadores la dividen entre Edad Media Alta y Edad Media Baja.

Consideramos que esta época es atractiva para los niños por el interés que muestran sobre la magia y fantasía que engloba este tema. Muchos de ellos sueñan con convertirse en príncipes y princesas como las que leen en los cuentos. Por ello, con este proyecto ayudaremos a que conozcan más sobre esta época.

¿Es realmente posible enseñar historia en Educación infantil? Hay numerosos autores que han investigado sobre la capacidad que tienen los niños para comprender la historia y el pasado.

Como dice Bardavio y González (2003):

En educación infantil se puede aprender a conocer a partir del descubrimiento de la historia. Los niños y niñas de estas edades pueden averiguar cosas que sucedieron hace mucho tiempo a través de las huellas que ha dejado el pasado y que han perdurado hasta nuestros días. Educar la mirada de los niños y niñas para que lean el paisaje, lo observen y lo comprendan no corresponde solamente a centros escolares de ciudades catedralicias o enclaves rurales o urbanos que se enorgullecen de contar con edificios notables o restos arqueológicos, sino que cada escuela está ubicada en un espacio que es posible interpretar históricamente. (citado en Feliu, Jiménez, Arbonés, Bardavio y Calabuig, 2015, p. 38).

Los niños aprenden poco a poco a que el tiempo puede medirse: minutos, horas, días, años y siglos. Ya que a los niños no les interesa el pasado porque no saben medirlo, estos aprenden a hacerlo cuando relacionan sus propias experiencias con las escalas de medición del tiempo: horas, días y años; ya que en realidad su vida está inmersa en el tiempo (Cooper, 2002).

Piaget (1952) realizó un estudio sobre la capacidad de los niños para colocar objetos en sucesión numérica. Esta competencia aplicada al contexto histórico hace que los niños sean capaces de secuenciar cronológicamente los acontecimientos.

A los 5 años, los niños ya son capaces [según Piaget (1956)] de comprender que los hechos pueden suceder a la vez, así como que las unidades de tiempo pueden sumarse.

Además, según Cooper (2002):

Los conceptos de tiempo son subjetivos y culturales. Dependen de las experiencias de los niños, de la lengua y de las oportunidades de escuchar y contar cuentos y poemas relativos al paso del tiempo y a otros tiempos, y de relacionar los hechos de sus propias vidas con el paso del tiempo. [...] La conciencia de los tiempos pasados depende también de la unidad familiar, de dónde residían los niños y del tiempo que lleven allí (p. 22-23). 
En definitiva, si creemos que es posible la enseñanza de la historia en la etapa de infantil. Como hemos visto, se puede trabajar tanto el tiempo como los contenidos históricos. Cooper (2002) propone tres líneas de acción didáctica para historia:

- Comprender los conceptos de tiempo y de cambio.

- Interpretar el pasado.

- Deducir e inferir información de las fuentes históricas.

En el actual Currículo de Educación Infantil, la historia en sí misma no constituye un área ni siquiera un contenido específico. Miralles y Rivero (2012) afirman que el actual Currículo español de Educación Infantil (Real Decreto 1630/2006, de 29 de diciembre, BOE 4 de enero de 2007) está dividido en tres áreas: Conocimiento de sí mismo y autonomía personal, Conocimiento del entorno y Lenguajes: comunicación y representación.

La enseñanza de la historia podría relacionarse con todas ellas ya que:

a) Contribuye a la construcción gradual de la propia identidad, aspecto relacionado con el área de Conocimiento de sí mismo y autonomía personal.

b) Ayuda a interpretar las huellas del pasado en el entorno y, por tanto, al conocimiento del entorno en sí mismo.

c) El trabajo con fuentes históricas y la elaboración de producciones propias del alumnado con información histórica implica el trabajo con diferentes formas de comunicación y de representación. (p. 82)

También se encuentra relacionado con los cambios en el modo de vida. Así, se podrá ' $r e c o n o c e r$ el patrimonio cultural del entorno, iniciar una enseñanza en el tiempo y trabajar aspectos de la vida cotidiana en diferentes épocas históricas"' (Miralles y Rivero, 2012, p. 82). De la misma manera, la enseñanza del tiempo está presente en todas las aulas de Educación infantil, a través de las rutinas que trabajamos diariamente o la celebración de los cumpleaños.

Por otro lado, a la hora de empezar a conocer nuestro pasado, lo más importante para los niños es que este sea lo más cercano posible. De esta manera, vamos a relacionar todos los contenidos tratados en este proyecto con el entorno de la Región de Murcia, ya que realizaremos una visita al castillo de Caravaca de la Cruz.

Durante la Edad Media, la Región de Murcia fue invadida por las tropas musulmanas a inicios del siglo XI y fue Abderramán II quien ordenó fundar Medina Mursiya como capital, la cual se convirtió en la ciudad más poblada e importante del sureste español. Más tarde, en el siglo XIII, vuelve a ser reconquistada por los cristianos.

De esta época, tenemos numerosos ejemplos en nuestra Región que pueden ser utilizados como recursos didácticos. Primero, tenemos numerosos yacimientos arqueológicos y monumentos, entre los que destacan: Siyasa (Cieza), Villa Vieja (Calasparra) y numerosos castillos como los de Jumilla, Aledo, 
Alhama de Murcia, Lorca, Moratalla y Caravaca de la Cruz. También contamos con el Museo de Santa Clara en Murcia donde se conservan restos de la época musulmana y la Fortaleza del Sol en Lorca. Por último, la Región de Murcia consta con diversas fiestas culturales como los Caballos del Vino en Caravaca de la Cruz o las Fiestas del Escudo en Cieza (Trigueros, Arias, Miralles, Molina y Rodríguez, 2013).

Además de conocer la cultura y el estilo de vida de la época medieval, los niños y niñas van a empezar a familiarizarse con los mapas y a saber interpretarlos. Catling (2013) señala que los mapas nos proporcionan las bases de nuestro conocimiento y, sobre todo, del conocimiento que tenemos sobre el lugar donde vivimos. Este último es vital para que los niños se sitúen y conozcan su región más cercana. Los niños comienzan a construir sus mapas mentales desde una edad muy temprana y hay evidencias de que la escuela necesita mejorar sus prácticas para ayudar a los niños a desarrollar su sentido de localización. Los mapas mentales de los niños incluyen su domicilio, el barrio donde viven y lugares cercanos que sean familiares para ellos. Conforme van creciendo e interactuando con diferentes lugares que les son desconocidos, esos mapas se vuelven más complejos y detallados.

Por último, cabe destacar que los niños no solamente aprenden a través de mapas, sino que Internet, programas de televisión, juegos de ordenador, libros o incluso (Cooper, 2002) historias los ayudan a comprender el medio en el que viven (Catling, 2013).

En conclusión, como hemos visto anteriormente, es importante que los niños aprendan desde edades tempranas a reconocer el entorno que les rodea y el pasado de este para que entiendan lo que está pasando y que las cosas no son fijas en el tiempo.

\title{
2 ACTIVIDADES
}

\subsection{ACTIVIDAD 1. LECTURA DE CUENTO:}

Según Miralles y Rivero (2012):

\begin{abstract}
La "narración de historias" puede ayudar a los niños a aprender cosas sobre tiempos, lugares y personas lejanos a su experiencia directa (Wood y Holden, 2007). Autores como Egan (1991 y 1994) han criticado que el alumnado sólo pueda aprender desde lo concreto, lo manipulativo y lo conocido. La imaginación es una buena herramienta de aprendizaje y de ahí la posibilidad de introducir la historia, en forma de narraciones, desde la Educación Infantil. La inclusión de leyendas populares, narración histórica, relatos mitológicos, etc. puede ser muy útil para que los niños comiencen a reconocer en las obras de arte a los diferentes personajes. (P.85)
\end{abstract}

\subsubsection{Desarrollo de la actividad:}

El director llega a clase y le entrega un pergamino la profesora (ANEXO 1). En él explica cómo una bruja secuestra a la princesa y los reyes han pedido ayuda para rescatarla. Los niños tendrán que investigar sobre los castillos y las características de su época para poder hacerlo. Al finalizar la jornada, la profesora entregará una carta a los padres (ANEXO 7) donde pida que ayuden a sus hijos a recaudar la 
información. Al día siguiente, entre todos se hará una puesta en común en la asamblea con lo que ha investigado cada alumno.

\subsubsection{Temporalización:}

La primera parte de la actividad (lectura del pergamino), tendrá una duración de 20 min. La segunda (la puesta en común), durará 30 minutos.

\subsubsection{Objetivos: (p9)}

1. Observar y explorar de forma activa su entorno físico, natural y social, desarrollar el sentido de pertenencia al mismo, mostrando interés por su conocimiento, y desenvolverse en él con cierta seguridad y autonomía.

3. Identificar y acercarse al conocimiento de distintos grupos sociales cercanos a su experiencia, a algunas características de sus miembros, producciones culturales, valores y formas de vida, generando actitudes de confianza, respeto y aprecio.

\subsubsection{Objetivos específicos:}

1. Buscar información en su entorno, fuera del contexto escolar.

2. Participación de los padres.

3. Escucha y participación activa.

4. Introducción a la vida de la época medieval.

\subsubsection{Contenidos: (p9)}

Bloque 2, primer ciclo.

-Participación en fiestas, juegos populares y salidas, disfrutando con las manifestaciones culturales de su entorno y comportándose de forma ajustada en cada una de ellas.

Bloque 3, segundo ciclo.

-Identificación de algunos cambios en el modo de vida y las costumbres en relación con el paso del tiempo.

\subsubsection{Competencias: (libro p104)}

-Aprender a aprender y a pensar.

De esta manera adquirirán nuevos conocimientos y razonarán sobre las nuevas ideas que están aprendiendo. 
-Aprender a comunicarse.

Tras la adquisición de los nuevos conocimientos están aprendiendo a explicarlos y a comunicarlos.

\subsubsection{Criterios de evaluación: (p10)}

1. Mostrar curiosidad e interés por el descubrimiento del entorno, y, progresivamente. Mediante este criterio de evaluación se valorará el grado de interés por el medio y los elementos que en él se encuentran y suscita en los niños.

\subsection{ACTIVIDAD 2. PIRÁMIDE:}

\subsubsection{Desarrollo de la actividad:}

La maestra entregará en clase una ficha individual a cada niño. Esta consiste en una pirámide jerárquica con cuatro estamentos, junto a las imágenes (personajes de la historia) que tendrán que colorear y colocar, y así razonar sobre los conocimientos adquiridos. (ANEXO 2)

\subsubsection{Temporalización:}

La actividad durará 40 minutos.

\subsubsection{Objetivos: (p9)}

5. Representar atributos de elementos y colecciones, y establecer relaciones de agrupamientos, clasificación, orden y cuantificación, iniciándose en las habilidades matemáticas.

\subsubsection{Objetivos específicos:}

1. Identificar los diferentes personajes de la historia.

2. Comprender la sociedad por estamentos.

\subsubsection{Contenidos:}

Bloque 3. Cultura y vida en sociedad.

Reconocimiento y valoración de algunas señas de identidad cultural propias y del entorno y participación activa e interesada en actividades sociales y culturales. Interés por el conocimiento y valoración de producciones culturales propias presentes en el entorno. 


\subsubsection{Competencias:}

2. Aprender a aprender y a pensar.

Al realizar esta actividad tendrán que razonar y pensar sobre el orden jerárquico, y de esta manera estarán propiciando su aprendizaje.

6. Aprender a hacer y emprender.

Con este tipo de actividades comenzarán a ser emprendedores y autónomos en la realización de actividades.

\subsubsection{Criterios de evaluación:}

3. Identificar y conocer los grupos sociales más significativos de su entorno, algunas características de su organización y los principales servicios comunitarios que ofrecen. Poner ejemplos de sus características y manifestaciones culturales, y valorar su importancia.

Se estimará igualmente la comprensión de algunas señas o elementos que identifican a otras culturas.

\subsection{ACTIVIDAD 3: MAQUETA}

\subsubsection{Desarrollo de la actividad:}

Los alumnos se encuentran sentados por equipos. Individualmente, decorarán y recortarán la cartulina (ANEXO 3) simulando la pared del castillo. Posteriormente, unirán sus partes para montar el castillo correspondiente a su equipo. La maestra les dará colores y materiales para la decoración necesarios para que lo corten y monten (tijeras y pegamento).

\subsubsection{Temporalización:}

La actividad durará 50 minutos.

\subsubsection{Objetivos: (P9)}

Área 2. Conocimiento del entorno.

1. Observar y explorar de forma activa su entorno físico, natural y social, desarrollar el sentido de pertenencia al mismo, mostrando interés por su conocimiento, y desenvolverse en él con cierta seguridad y autonomía.

4. Indagar el medio físico manipulando algunos de sus elementos, identificando sus características y desarrollando la capacidad de actuar y producir transformaciones en ellos.

Área 3. Lenguajes: comunicación y representación: 
6. Desarrollar la curiosidad y la creatividad interactuando con producciones plásticas, audiovisuales y tecnológicas, teatrales, musicales, o danzas, mediante el empleo de técnicas diversas.

\subsubsection{Objetivos específicos:}

1. Construir su propio castillo.

2. Trabajar en equipo.

\subsubsection{Contenidos:}

Bloque 3. Cultura y vida en sociedad.

-Observación de necesidades, ocupaciones y servicios en la vida de la comunidad. Conocimiento de que las personas se organizan en distintos grupos sociales. Deseo de participación en ellos.

-Identificación de algunos cambios en el modo de vida y las costumbres en relación con el paso del tiempo.

- Identificación de algunos cambios en el modo de vida y las costumbres en relación con el paso del tiempo.

\subsubsection{Competencias:}

-Aprender a hacer y emprender.

Con este tipo de actividades comenzarán a ser emprendedores y autónomos en la realización de actividades.

\subsubsection{Criterios de Evaluación:}

Mediante este criterio de evaluación se valorará el grado de interés del medio físico y los elementos que en él se encuentran suscita en los niños y niñas; si detectan y se sienten motivados por manipular los objetos físicos, por saber cómo son y cómo se comportan en función de sus cualidades y atributos, si establecen relaciones entre éstos (forma, color, tamaño, peso...).

\subsection{ACTIVIDAD 4: MANUALIDAD (CORONA)}

\subsubsection{Desarrollo de la actividad:}

La maestra previamente encargará a los niños y padres que busquen en casa materiales para decorar su propia corona (ANEXO 4). Al día siguiente, les reparte una corona en blanco. Una vez decorada, la recortarán a su medida para colocársela con una goma. Saldrán a la asamblea y debatirán sobre quién llevaba corona en la Edad Media; de esta forma se pondrán en el papel de reyes y reinas. 


\subsubsection{Temporalización:}

La actividad durará 45 minutos.

\subsubsection{Objetivos:}

Área 2. Conocimiento del entorno.

1. Observar y explorar de forma activa su entorno físico, natural y social, desarrollar el sentido de pertenencia al mismo, mostrando interés por su conocimiento, y desenvolverse en él con cierta seguridad y autonomía.

4. Indagar el medio físico manipulando algunos de sus elementos, identificando sus características y desarrollando la capacidad de actuar y producir transformaciones en ellos.

Área 3. Lenguajes: comunicación y representación

2. Experimentar y expresarse utilizando los lenguajes corporal, plástico, musical y tecnológico, para representar situaciones, vivencias, necesidades y elementos del entorno y provocar efectos estéticos, mostrando interés y disfrute.

6. Desarrollar la curiosidad y la creatividad interactuando con producciones plásticas, audiovisuales y tecnológicas, teatrales, musicales, o danzas, mediante el empleo de técnicas diversas.

\subsubsection{Objetivos específicos:}

1. Hacer el papel de reyes y reinas por un día.

2. Decorar la corona a su gusto.

\subsubsection{Contenidos:}

Área 2

-Reconocimiento y valoración de algunas señas de identidad cultural propias y del entorno y participación activa e interesada en actividades sociales y culturales.

-Interés por el conocimiento y valoración de producciones culturales propias presentes en el entorno.

- Identificación de algunos cambios en el modo de vida y las costumbres en relación con el paso del tiempo.

Área 3. Lenguajes: Comunicación y Representación.

-Disfrute en la elaboración de proyectos colectivos y en la observación de diferentes producciones artísticas presentes en el entorno. 
-Utilización y valoración progresiva de la lengua oral para evocar y relatar hechos, para explorar conocimientos, expresar y comunicar ideas y sentimientos y como ayuda para regular la propia conducta y la de los demás.

\subsubsection{Competencias:}

-Aprender a comunicarse:

Tras la adquisición de los nuevos conocimientos están aprendiendo a explicarlos y a comunicarlos.

-Aprender a hacer y emprender: Con este tipo de actividades comenzarán a ser emprendedores y autónomos en la realización de actividades.

\subsection{ACTIVIDAD 5. EXCURSIÓN}

\subsubsection{Desarrollo de la Actividad:}

Tras varias sesiones tratando la Edad Medieval, los niños ya están preparados para resolver el enigma de la princesa. Por ello, la profesora les lee una carta (ANEXO 5) que ha dejado la bruja. En ella indica dónde ha encerrado a la princesa, gracias a un mapa que ha repartido por el patio. Los niños buscarán las partes y juntarán el mapa para averiguarlo.

El mapa ANEXO lleva al Castillo de Caravaca de la Cruz. Se ha programado una excursión para ir a visitarlo, la maestra explicará a los alumnos la ubicación y una breve historia sobre la visita que van a realizar para seguir conociendo la cultura medieval de la región.

Tras la visita, se encontrarán con una muñeca, simulando a la princesa del cuento. Los niños se la llevarán a clase y la habrán rescatado todos juntos.

Temporalización:

La primera parte de la actividad, que engloba la lectura y búsqueda del mapa, durará 50 minutos. La segunda parte (la excursión), durará la jornada completa.

\subsubsection{Objetivos:}

Área 2. Conocimiento del entorno.

1. Observar y explorar de forma activa su entorno físico, natural y social, desarrollar el sentido de pertenencia al mismo, mostrando interés por su conocimiento, y desenvolverse en él con cierta seguridad y autonomía.

3.Identificar y acercarse al conocimiento de distintos grupos sociales cercanos a su experiencia, a algunas características de sus miembros, producciones culturales, valores y formas de vida, generando actitudes de confianza, respeto y aprecio. 
7. Conocer y valorar los componentes básicos del medio natural y algunas de sus relaciones, cambios y transformaciones, desarrollando actitudes de cuidado, respeto y responsabilidad en su conservación.

\subsubsection{Contenidos:}

Bloque 3. Cultura y vida en sociedad

Reconocimiento y valoración de algunas señas de identidad cultural propias y del entorno y participación activa e interesada en actividades sociales y culturales. Interés por el conocimiento y valoración de producciones culturales propias presentes en el entorno.

Identificación de algunos cambios en el modo de vida y las costumbres en relación con el paso del tiempo.

\subsubsection{Competencias:}

-Aprender a aprender y a pensar.

De esta manera adquirirán nuevos conocimientos y razonarán sobre las nuevas ideas que están aprendiendo.

-Aprender a vivir juntos.

Esta actividad requiere una convivencia grupal donde los niños tendrán que convivir conjuntamente.

\subsubsection{Criterios de evaluación:}

Mostrar curiosidad e interés por el descubrimiento del entorno, y, progresivamente: identificar, discriminar objetos y elementos del entorno inmediato y actuar sobre ellos.

Es importante, también, la observación de la actitud y disposición favorable que manifiesten niños y niñas hacia los elementos del medio natural, si son capaces de verbalizar algunas razones que deben llevarnos a su cuidado y protección, así como si participan activamente y de buen grado en propuestas de acción para respetar y cuidar el medio ambiente.

\section{CONCLUSIÓN}

Para concluir este trabajo, queremos destacar que creemos que el ABP es una metodología muy buena para trabajar en el aula de Educación Infantil, ya que nos permite que el niño sea participe activo en su proceso de enseñanza-aprendizaje. Es una forma muy dinámica y atractiva para que los niños sean protagonistas y, a la vez, los padres se involucren también en ese proceso. 
Además, el tema que hemos escogido es muy atractivo para los niños y niñas de 5 años que se están iniciando en el mundo de fantasía, como hemos mencionado anteriormente. 


\section{REFERENCIAS}

Catlin, S. (2013). Learning about places around the world. En Scoffham, S. (Ed.), Teaching Geography Creatively. (pp. 59-71). Londres, Reino Unido: Routledge.

Cooper, H. (2002). History in the early years. (Trad. cast.: Didáctica de la historia en la educación infantil y primaria. Madrid, España: Morata, 2002).

Feliu, M., Jiménez, L., Arbonés, G., Bardavio, A., \& Calabuig, S. (2015). Ciencias sociales y educación infantil (3-6). Barcelona, España: Graó.

Piaget, J. (1952). The Child's Conception of Number, Londres, Routledge. (Trad. cast.: Génesis del número en el niño. Buenos aires, Guadalupe, 1975).

Piaget, J. (1956). The Child's Conception of Time, Londres, Routledge. (Trad. cast.: El Desarrollo de la noción de tiempo en el niño. México, Fondo de Cultura Económica, 1978).

Restrepo, B. (2005). Aprendizaje basado en problemas (ABP): una innovación didáctica para la enseñanza universitaria. Educación y educadores. Volumen 8. p. 2-3. Recuperado de http://educacionyeducadores.unisabana.edu.co/index.php/eye/article/view/562/654

Trigueros, F.J., Arias, L., Miralles, P., Molina, S., \& Rodríguez, R.A. (2013.) Didáctica De Las Ciencias Sociales En Los Cursos De Grado De Educación Infantil. Murcia, España: Diego Marín.

\section{ANEXOS}

ANEXO 1

Érase una vez, en un reino muy lejano, vivía una hermosa princesa en un castillo. Su padre, el rey, era un hombre muy mayor y muy sabio que llevaba muchos años gobernando al reino, junto a su madre, la reina. En este, vivían muchísimos ciudadanos; algunos se dedicaban a sembrar y a cuidar a los animales para poder alimentar al reino y otros eran los encargados de fabricar las espadas que utilizaban los caballeros para poder defenderlos.

Un día, una bruja malvada se presentó a la entrada del reino. Esta engañó a la princesa y ahora está encerrada en la torre de un castillo mágico. Su familia está desesperada y no sabe qué hacer. Por favor, necesitamos de vuestra ayuda. ¿Vais a intentar recatarla?

\section{ANEXO 2}




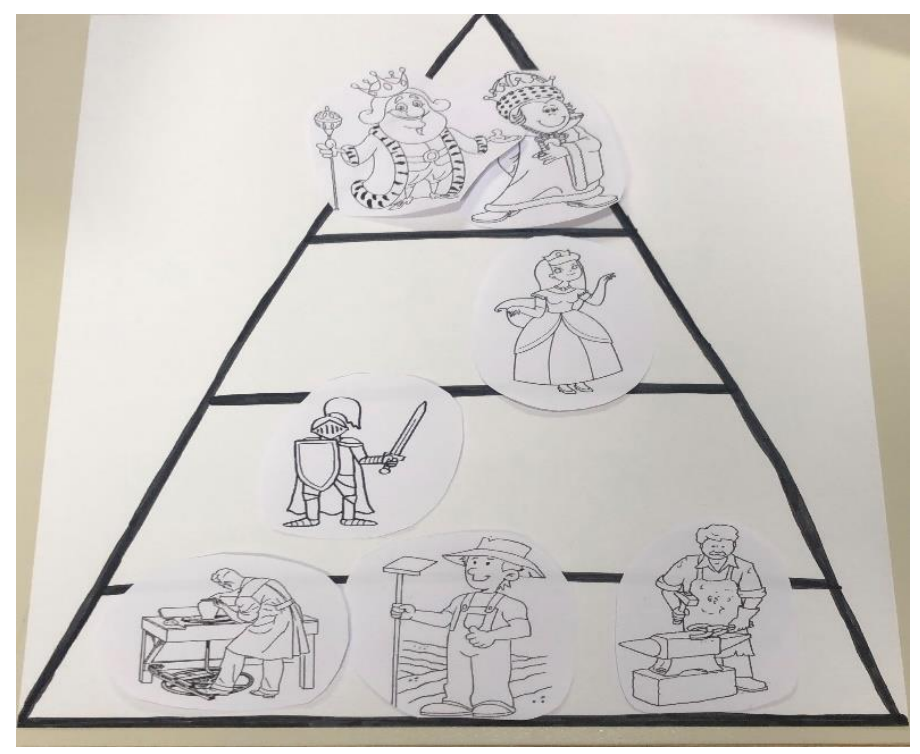



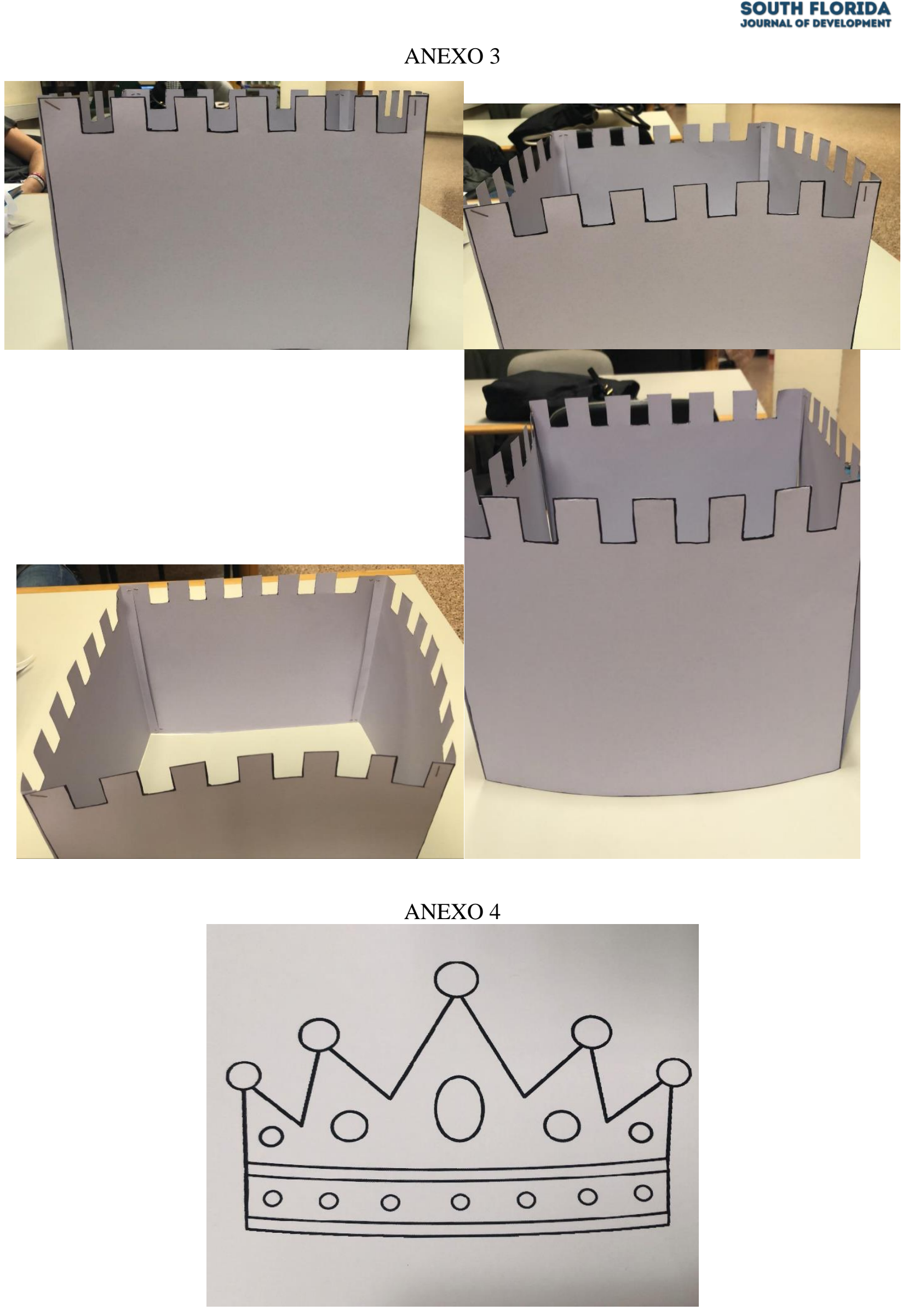


\section{ANEXO 5}

Buenos días chicos, soy la bruja. Si vuestra maestra os está leyendo esta carta, significa que habéis aprendido mucho sobre la época medieval. Para felicitaros, os propongo un juego. He escondido un mapa en el patio del cole. Si sois buenos exploradores, podéis encontrar dónde está la princesa.

\section{ANEXO 6}

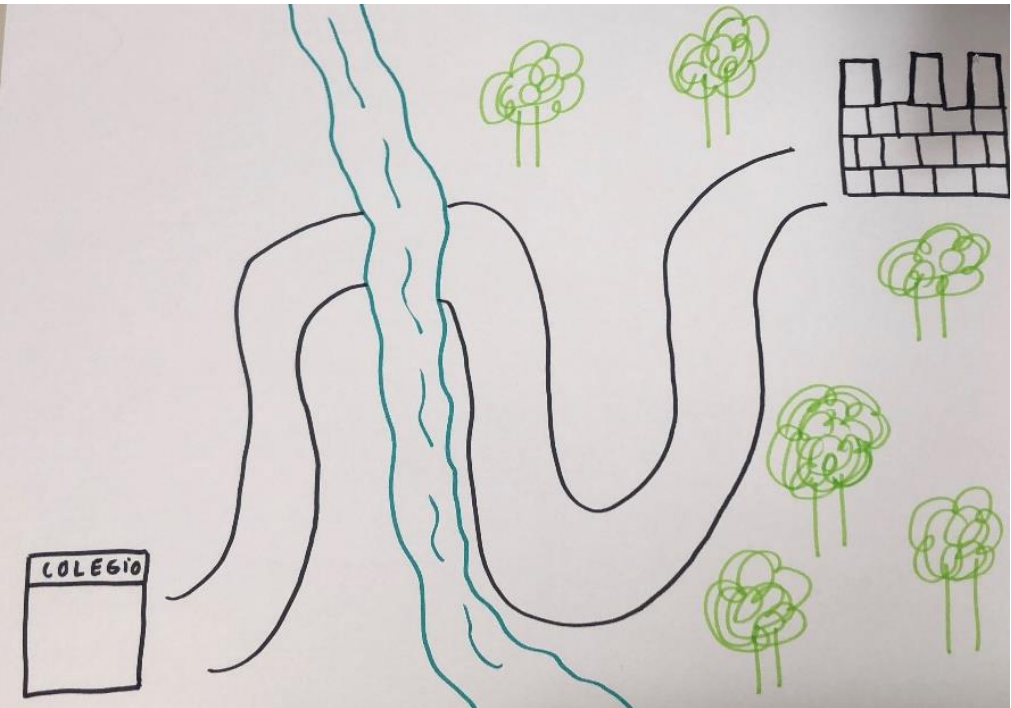

ANEXO 7

Papás y mamás vamos a comenzar un proyecto sobre la época medieval: los castillos, los príncipes, princesas...

Necesitamos de vuestra ayuda para poder desarrollarlo. Es importante que les ayudéis a recaudar información, todo tipo de material o datos nos sirve: cuentos, películas, leyendas, imágenes... para que trabajéis conjuntamente y lo podamos poner en común en clase.

Pedimos vuestra colaboración, igracias!.

\section{AUTOEVALUACIÓN}

\section{Presentación del trabajo y redacción académica de los contenidos}

\section{Indicador}

1. Portada del trabajo

2. Índice estructurado y paginado

3. Márgenes del texto, formato y espacio del papel
Puntuación máxima
Puntuación otorgada

7p. Cumple con todos los requisitos de presentación.

8p. Está perfectamente estructurado y paginado.

10p. Hemos respetado la normativa APA en este aspecto. 
4. Redacción estructurada y coherente. Fundamentación teórica

SUBTOTAL

\section{Dominio de la materia}

\section{Indicador}

1. Fundamentación teórica

2. Citación de autores. Normas

APA

3. Unidad didáctica muy estructurada

\section{Puntuación máxima} 10

1. Se utilizan citas textuales impresas y online

2. Recursos creativos y novedosos en las actividades a realizar
25 p. Creemos que hemos encadenado la fundamentación de manera lineal con contenidos acordes al tema, explicando los contenidos de manera ordenada.

50 Puntos

\section{Puntuación otorgada}

11p. Hemos utilizado diversas fuentes y por ello distintos puntos de vista, otorgando variedad a esta.

10p. Hemos citado a todos los autores indicados y que además han aportado algo relevante a los temas tratados en este trabajo.

7p. Consideramos que está bien estructurada pues los títulos de cada apartado son claros y concisos lo que facilita el entendimiento en gran medida.

10p. Hemos enseñado con nuestras actividades y fundamentación todos los conceptos relevantes de la materia.

38

\section{Puntuación otorgada}

10p. Hemos utilizado tanto citas de textos impresos como online.

8p. Consideramos que los materiales que hemos creado y utilizado para las actividades son útiles para la 